\title{
MOVIMENTOS E(M) DESERTOS: AS TRILHAS DA EXISTÊNCIA ENTRE QUILOMBOLAS DE GOIÁS ${ }^{1}$
}

\author{
Daniela Carolina Perutti ${ }^{1}$ \\ ${ }^{1}$ Universidade Federal de São Paulo, SP, Brasil
}

Em 29 de outubro de 2015, uma reportagem da rede de TV Anhanguera (afiliada da Globo) narrava a história de Antônio, 57 anos, que há 25 teria abandonado sua casa na cidade de Nova Roma (Goiás), sua esposa e seu filho para viver, literalmente, em um buraco. Partira para o meio do mato e ali fizera sua morada, embaixo do chão. O buraco tem uma abertura na parte superior, diz Antônio, para que possa estar em contato permanente com o céu. ${ }^{2}$ Sua irmã entrou na justiça para que ele, diagnosticado com esquizofrenia paranoide, tivesse acesso retroativo ao Benefício de Prestação Continuada, fornecido pelo antigo Ministério do Desenvolvimento Social à pessoa com deficiência.

A reportagem narra o encontro do juiz, Everton, responsável por julgar o caso, e o ermitão, como Antônio fora chamado. Segundo tal narrativa, o juiz teria ficado surpreso com o uso de técnicas apuradas para a construção do buraco, com sistema de escoamento de água, além de outras tecnologias, por uma pessoa considerada delirante, "sem noção da realidade".

Antônio era garimpeiro e, quando estive pela primeira vez em trabalho de campo, ${ }^{3}$ uma das versões que me foram contadas sobre a origem de sua loucura é a de que, no passado, teria encontrado uma quantidade nada desprezível de ouro. Em seguida, apareceu o diabo na forma de homem fazendo-lhe uma proposta que, por sua vez, fora recusada e, desde então, foi "endoidecendo". Parou de comer carne e começou a dormir no chão, até construir o buraco. Sua base de alimentação passou a ser a pimenta malagueta, acompanhada por arroz e vegetais. Quando distante de seu buraco, ele faz questão de dormir ao relento para ter contato direto com o céu, e diz receber mensagens do trovão. 
Não pretendo me aprofundar, aqui, nas histórias de e sobre Antônio, ricas em detalhes e diferentes versões, mas sim fazer uma indagação: por que esse homem causa tanto medo entre meus interlocutores novaromanos, mais medo do que outras pessoas da cidade com fama de serem nervosas, "agitadas", "caçadoras de confusão"? ${ }^{4}$ Uma série de razões pode ser conjecturada para isso. Antônio produz inversões, recusando a carne como base fundamental de dieta, tendo no tempero (pimenta) seu prato principal. Recusa também a casa como espaço de habitação, tendo escolhido um buraco no meio do mato para viver. Junto com a casa, recusa, ainda que não completamente, a vida nas ruas da pequena cidade, em fazendas ou povoados.

Assim, Antônio lança à luz, com seu modo de vida, uma questão incômoda que atravessa, de uma forma ou de outra, a maior parte dos novaromanos: o "deserto". Antônio toma o buraco para si, intensificando uma potencialidade de Nova Roma da qual seus habitantes procuram se afastar.

A ideia de que o Brasil mais a oeste é um grande vazio demográfico que necessita ser ocupado e codificado parece uma constante, e norteou políticas públicas e de colonização. Do bandeirantismo à marcha para o Oeste da Era Vargas, passando pela construção de Brasília, estamos às voltas com a imagem do "deserto a reclamar posse e conquista", como caracterizou Juscelino Kubitschek em seu discurso de inauguração da nova capital federal (2010 [1960]), bem no centro de Goiás. Interessa-me, contudo, olhar o deserto não do ponto de vista do Estado e de agentes da colonização, que ao enunciarem lugares como desertos, negam coetaneidade ${ }^{5}$ a gentes e seres que ali vivem fora de seu alcance (seriam parte de um passado fadado a desaparecer), mas sim daqueles que o habitam e, por vezes, torcem seus sentidos mais correntes. Parto do entendimento de que o deserto é frequentado em movimentos cujas intensidades lhe são próprias.

Entre os habitantes de Nova Roma, no nordeste de Goiás, distante 254 quilômetros de Brasília e onde Antônio fez o seu buraco, há uma queixa frequente de que o lugar está sem movimento, em vias de acabar, de virar um deserto. Dizem que ali não existe uma firma, que nunca foi caminho de uma rodovia, que o garimpo de cassiterita (cujo ápice foi nos anos 1980) entrou em declínio, e que a terra padece na seca, sendo a cada ano mais intensa. ${ }^{6}$ Em certas narrativas, Nova Roma é quase um não lugar, pois marcado fundamentalmente pela falta. É segundo esta percepção que os nova-romanos buscam colocá-lo em movimento, ou movimentam-se de lá, seja nas "andanças" para Brasília, Goiânia, oeste da Bahia e fazendas vizinhas, seja no período de eleições municipais (o "tempo da política"7) e nos tempos de festa, marcados por intensa circulação de pessoas e trocas de 
ajudas, quando a cidade fica cheia e a percepção de deserto, minimizada. Para os munícipes, deserto impõe movimento: pessoas se movimentam em suas "andanças" para fugir de "desertos", um lugar se afasta do "deserto" quando tem "movimento".

Imagem 1: Bendito de Mesa da Folia de São Sebastião de Família Magalhães (Daniela Perutti 2013)

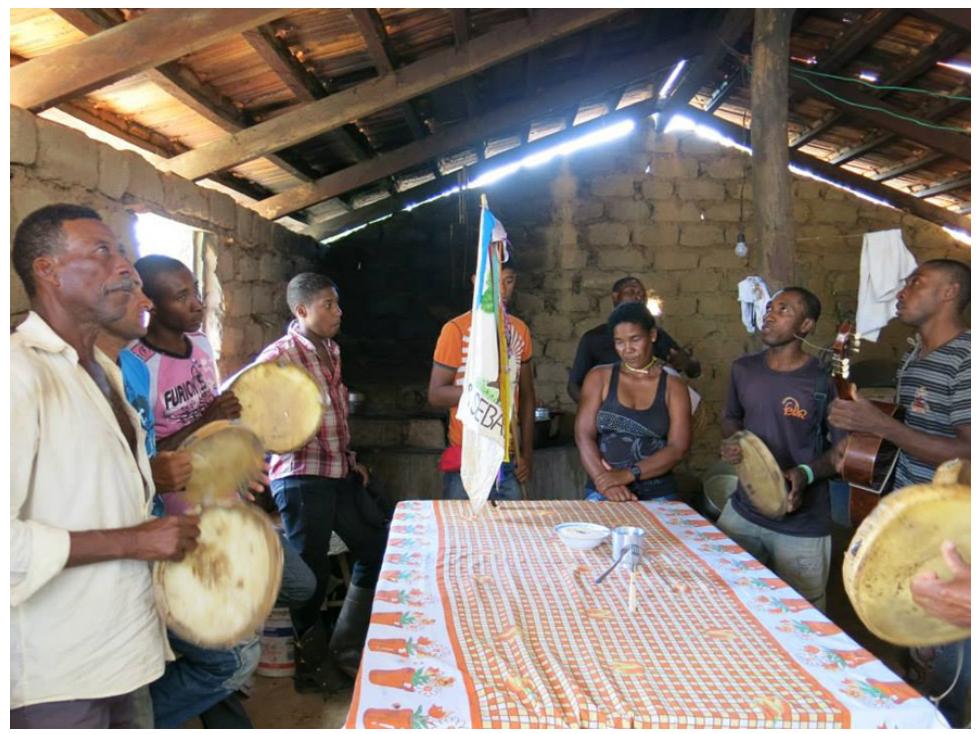

Tendo em vista os dados populacionais, Nova Roma pode ser considerada pouco povoada, assim como toda a região do nordeste goiano. $\mathrm{O}$ censo do IBGE de 2010 mostra que o município contava com uma população de 3.471 pessoas, e uma densidade demográfica de 1,63 habitante por quilômetro quadrado. Ao chegar à cidade pela primeira vez, compartilhei dessa percepção: rodam-se muitos quilômetros em estrada precária com pouca ou nenhuma presença humana. Além disso, com terreno arenoso e secas cada vez mais intensas, poucos são os lugares propícios para roças ou pastos adequados para o gado, que padece nos períodos de falta de chuva. 
Mapa 1: Estado de Goiás com a localização do município de Nova Roma. Extraído de https://pt.wikipedia.org/wiki/Nova_Roma

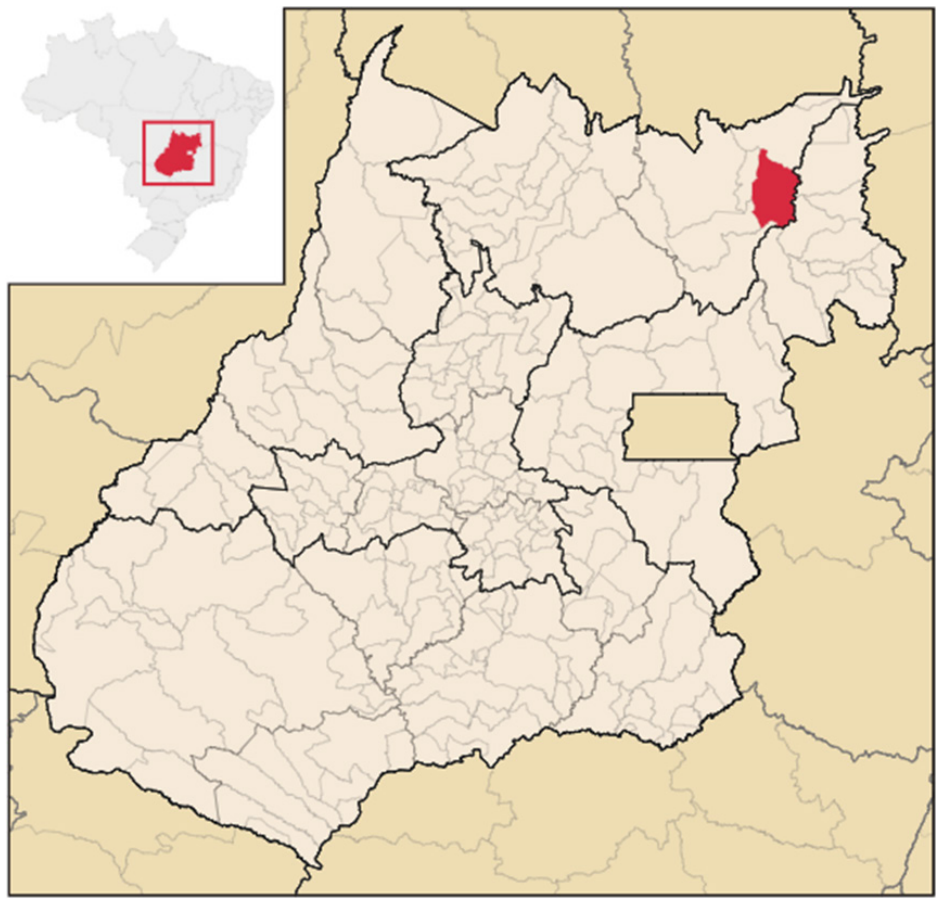

O garimpo de cassiterita, que teve início no final dos anos de 1970, é tido como período de exceção em tais narrativas sobre a região. O minério foi ali descoberto por uma expedição da Vale do Rio Doce e, logo após, a empresa construiu uma estrada de terra que dava acesso à localidade. Em conversa com Pedro Jacobi, geólogo que chefiou a expedição, soube que lá não existia até então qualquer estrada carroçável, e parte da população dos povoados próximos do garimpo nunca havia visto um automóvel até a chegada da equipe no local. Imagens como a do deserto, isolamento e falta de contato com a civilização foram usadas pelo geólogo para descrever a região.

A descoberta foi rapidamente propagada, o que ocasionou um deslocamento de milhares de garimpeiros vindos de diferentes estados do nordeste brasileiro, que exerceram pressão sobre os geólogos da Vale. A empresa, que na época pertencia ao Estado, optou por se retirar da região e assim evitar um conflito de grandes proporções. Mais de 10 mil pessoas (alguns falam em 15, 20 mil, mas não encontrei uma estimativa oficial) ocuparam as áreas de garimpo durante um período de quase vinte anos, dentre as quais, seu Antônio. ${ }^{8}$ Foram consideráveis os impactos de uma ocupação dessas proporções em um município que contava com menos da 
metade de habitantes em todo o seu território. Um ex-secretário da prefeitura conta que coisas nunca vistas em Nova Roma, como cinemas, prostíbulos e comércio em larga escala, estavam presentes na área do garimpo.

Com a mesma velocidade com que chegou, em vista da queda do preço da cassiterita no início dos anos 1990, o garimpo entrou em declínio, deixando apenas uma área devastada e com buracos sobre os morros, além de alguns moradores, ex-garimpeiros, que viraram comerciantes e ali se estabeleceram. Hoje, as ruínas do garimpo sobre os morros de Nova Roma compõem a imagem de deserto compartilhada por meus interlocutores.

Em diversas ocasiões, fui desencorajada de pesquisar a região pelos próprios nova-romanos, por considerarem que ali, naquele "fim de mundo", não teria mais nada que pudesse ser do interesse de uma pesquisadora. Regiões vizinhas, como o Sítio Histórico do quilombo do Kalunga, teriam mais "cultura", municípios mais ao sul do estado teriam mais "movimento" e mais "progresso". Contudo, quanto mais tentavam me dissuadir da pesquisa, mais aumentava meu interesse quanto ao problema de se habitar o deserto.

\section{Família Magalhães: tecer amizade para sair do deserto}

Minha pesquisa de doutorado teve como enfoque privilegiado uma parte específica desses munícipes, a saber, os membros de Família Magalhães - grupo autoidentificado quilombola que habita o norte do município, a Fazenda Lavado. Lá, a maioria das habitações está disposta entre a estrada de terra e o rio Paranã, em uma extensão de 4 a 5 quilômetros. Não há serviços básicos no Lavado, como posto de saúde ou comércio. A escola comunitária de Ensino Fundamental I foi desativada em 2008, obrigando as mulheres e seus filhos em idade escolar a ficarem durante a semana na área urbana de Nova Roma, a 35 quilômetros do Lavado, em casas de parentes, de aluguel ou próprias. Até o término de minha pesquisa de campo, a prefeitura fretava um carro para levar as crianças e suas mães para Nova Roma aos domingos, e as trazia de volta à comunidade na sexta-feira. Isto porque não há qualquer tipo de transporte público que passe pelo Lavado, sendo necessário o uso de carros particulares para os deslocamentos. Como a maior parte dos Magalhães não dispõe de carro, as caronas são uma forma importante de viabilizar as saídas, sempre planejadas previamente. Por vezes, alguns membros do grupo partem para a sede do município a pé ou "em lombo de burro". 
O grupo é originário dos kalungas, negros escravizados em fuga que viviam, desde o século 17, escondidos pelas serras e pelos vales do rio Paranã, mais ao norte e a oeste de Nova Roma. Hoje, o Kalunga é considerado o maior quilombo do Brasil, tem uma ampla área tombada como Sítio Histórico e Patrimônio Cultural (Lei Estadual n. 11.409 de 21 de janeiro de 1991), e suas terras estão em processo de regularização fundiária, como quilombola, pelo governo federal, tendo sido, até o momento, parcialmente titulada. Já Família Magalhães aguarda desde 2004 pela titulação de suas terras, cujo processo de desapropriação encontrava-se paralisado até a conclusão deste artigo.

Mapa 2: Localização do território Kalunga. Extraído de <porlatierra.org>

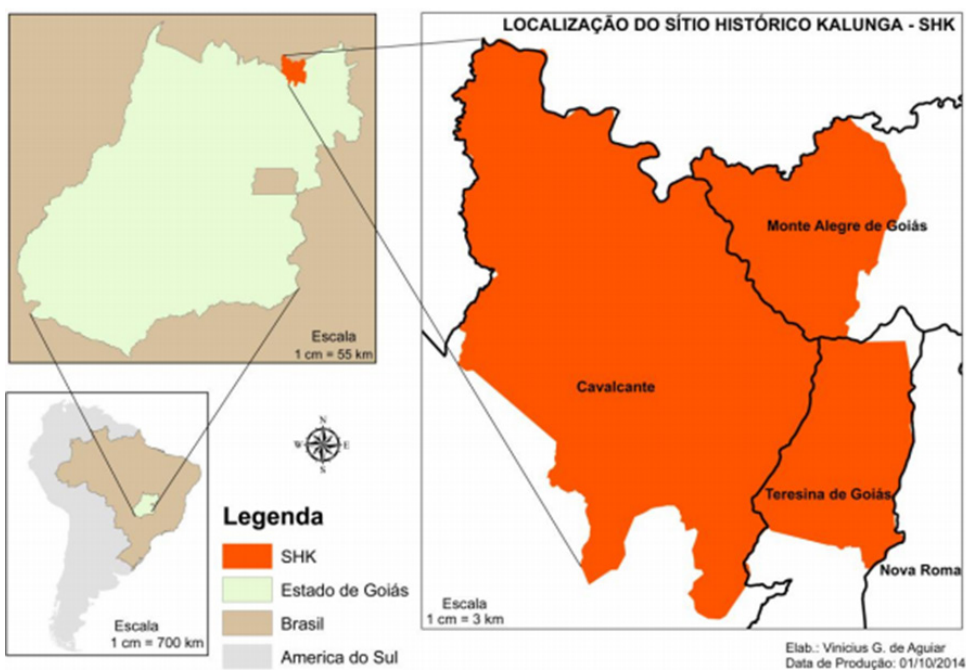

Família Magalhães compartilha dessa percepção generalizada de seus comunícipes de que o lugar estaria perto do fim, mas a ela reage de forma específica, pois gostam de se definir como pessoas "amigueiras". Consideram que esse modo de ser é uma herança do falecido João Magalhães, ancestral fundador da família. Seu Magalhães fazia amizades (em composição com relações de afinidade, vicinalidade e compadrio) em razão dos saberes específicos que possuía como parteiro, benzedor, curandeiro, tudo sob um temperamento calmo e agregador. Demonstrei em trabalhos anteriores (Perutti 2015, 2018) que a amizade (ser "amigueiro", ter muito amigo) aparece para os Magalhães como um modo de estar no mundo e gerir relações com seus outros, trazendo-os para o terreno do familiar; um valor moral; um sinal diacrítico; um recurso acionado retoricamente de modo a contrabalançar desigualdades. É comum ouvir de meus interlocutores que 
eles não têm dinheiro, mas amigos, e que as amizades seriam o seu maior bem. Ao se definirem como "amigueiros", povoam e trazem movimento às suas vidas, criam um território existencial que os afasta do deserto e, ao mesmo tempo, o toma como condição original de seu modo de ser e de se relacionar, como veremos. De acordo com Sebastiana:

É melhor ter amigo que dinheiro. [...] Nós, graças a Deus, temos amigo! Não adianta nada ter dinheiro se não tem amigo. Eu nunca tive vontade de ser rica, o que eu sempre quis era não ter precisão, não ter que ir pedir na casa dos outros.

Muito poderia ser dito sobre a relação de meus interlocutores com o dinheiro em diferentes contextos. Para ser breve, destaco que amizade e dinheiro (propriedade) são contrapostos com frequência, sendo o segundo um potencial produtor de desertos. O garimpo de cassiterita e a corrida pelo dinheiro rápido teriam sido responsáveis por desertificar a região. Uma terra adquirida por meio de um ato de compra desacompanhado de relações com a mesma (morar, fazer roças, ter criações) e com o entorno é entendida como deserta, e é tratada como sinônimo de terra devoluta. Sebastiana costuma dizer que antes o mundo era cheio de gente e sem cercas, e que quanto mais cercas há na terra, menos gente para habitá-la.

Nos anos 1950, João e Sebastiana fixaram-se na Fazenda Lavado tendo em vista que o proprietário aparecia no local apenas esporadicamente. O compadre de João, então gerente daquelas terras, convidou-o para que ali criassem porcos. Após um tempo, mudaram-se para regiões vizinhas, mas, por insistência da esposa, que àquela altura já tinha cinco filhos, fixaram-se definitivamente no Lavado. "Quem não para quieto não junta monturo" - explicou-me Sebastiana. ${ }^{9}$ Era hora, portanto, de deixar de lado casas erguidas e desmanchadas ao sabor dos movimentos para criar permanência, juntar monturo.

Tendo voltado para o Lavado, ali se estabeleceram sem a necessidade de uma contrapartida ao proprietário. Até que, após sucessivas vendas daquelas terras, passaram a sofrer ameaças de despejo por parte de supostos herdeiros de um falecido dono. O reconhecimento como quilombolas, com direito à titulação coletiva das terras que habitam pelo governo federal, de acordo com o artigo 68 do Ato das Disposições Constitucionais Transitórias, ${ }^{10}$ foi o que garantiu que não fossem expulsos da localidade, conforme discuti em trabalho anterior (Perutti 2015).

A Fazenda Lavado, hoje ocupada integralmente por descendentes e afins de João e Sebastiana, está longe de ser um território homogêneo do ponto de vista das relações que estabelecem com os de fora. Até o término da pesquisa, a família era cindida entre os "de cima" e os "de baixo" em 
razão de alianças políticas locais, e tal cisão diz respeito, dentre outras coisas, às relações de vicinalidade que cada parte da família mantinha com diferentes posseiros e pequenos proprietários de maior poder econômico, ligados à política local e que se tornaram também seus correligionários. Por exemplo, um dos filhos de Sebastiana que habita a extremidade "de cima" do território cultivava relações de troca com o vizinho mais próximo então vinculado ao PMDB, colocando seu gado no pasto dele em troca de vigiar a área e prestar-lhe pequenos serviços. Estabeleceu-se, portanto, uma amizade entre os dois, que também se converteu em aliança política. Já os moradores de casas situadas mais abaixo do rio Paranã prestavam serviços e recebiam ajuda de vizinhos localizados em área mais próxima de suas casas e vinculados ao PSDB, tendo se tornado aliados políticos destes.

Se as relações de vicinalidade não eram homogêneas e se converteram, em alguma medida, em alianças políticas repletas de tensões entre os lados da família, quando a equipe do Incra esteve na região para delimitar a área a ser titulada, os Magalhães recusaram incluir no montante terras vizinhas ocupadas no passado com roçados e pastos e perdidas ao longo do tempo, não importando se eram de seus aliados ou opositores políticos. ${ }^{11}$ Tal atitude se justificou em função de que ter mais terras significava desapropriar vizinhos, e relações de vicinalidade ajudam a dar sentido ao Lavado, a manter seu modo "amigueiro" de ser, fazendo do lugar menos deserto. Além do mais, não seria vantajoso criar tensões com vizinhos de maior poder econômico, e a atitude "amigueira" seria uma forma de contrabalançar desigualdades, convertendo um possível interesse por terras em generosidade e desprendimento. O filho de Sebastiana que coloca o gado no terreno do vizinho disse preferir manter o território menor a perder o amigo e correligionário. Sua escolha foi aceita pelos Magalhães de lado oposto, entendendo que o argumento de que "não se pode jogar pedra em amigo" (Almeida 2008) deveria preponderar. Assim, para que determinado espaço se realize enquanto lugar, é necessário movimentá-lo por meio de relações, ao passo que lugares sem movimento demandam que se saia de lá.

Movimento é, portanto, entendido por meus interlocutores tanto como "andança" (deslocamento físico de pessoas de um lugar ao outro), quanto por algo similar ao que Ingold chamou de "nós", lugares onde habitantes se encontram e trilhas são entrelaçadas, ou ainda, um condensado de pessoas e relações. Diz o autor: 
Prosseguindo ao longo de um caminho, cada habitante deixa uma trilha. Onde habitantes se encontram, trilhas são entrelaçadas, conforme a vida de cada um vincula-se à de outro. Cada entrelaçamento é um nó e, quanto mais essas linhas vitais estão entrelaçadas, maior a densidade do nó. [...] Lugares, então, são como nós, e os fios a partir dos quais são atados são linhas de peregrinação (Ingold 2015:219-220). ${ }^{12}$

Tendo em vista esse modo de ser e de se territorializar de Família Magalhães, meu próximo passo será o de analisar as relações possíveis entre movimento e deserto. Buscarei explorar os sentidos de deserto como fim iminente, como travessia e como origem, bem como qualificar os modos de andar e de permanecer de meus interlocutores.

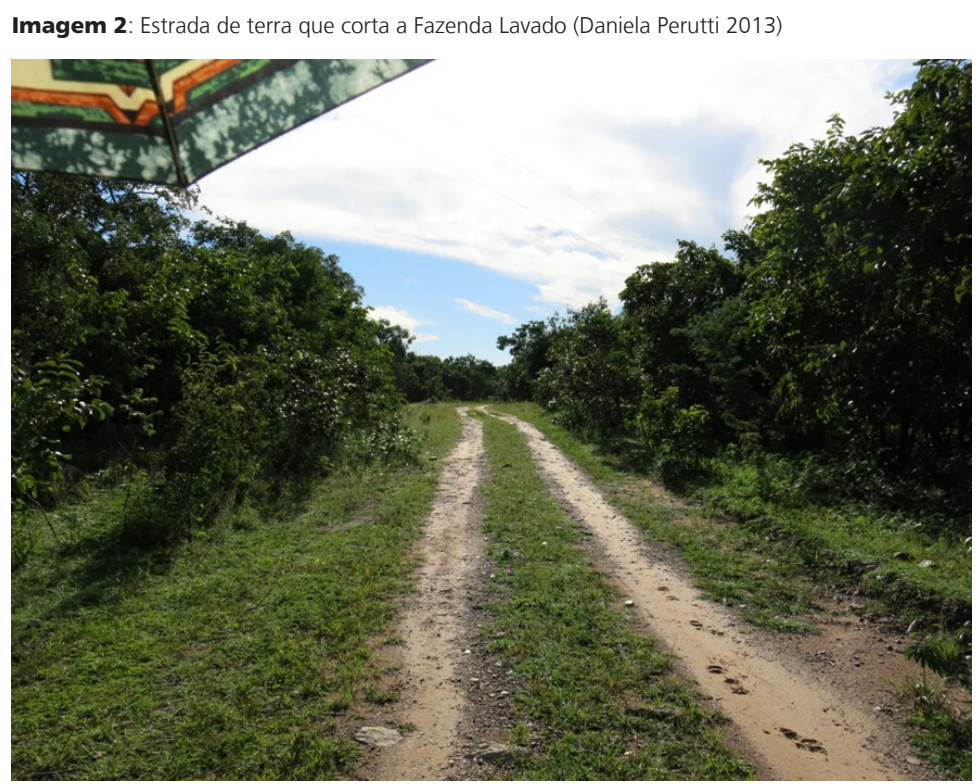

\section{Da migração como categoria autoevidente à mobilidade como modo de vida}

A temática do deslocamento de pessoas ou grupos foi exaustivamente tratada nas ciências sociais segundo as noções de migração (e seus derivados imigração e emigração) e êxodo. De acordo com Palmeira e Almeida (1977), em uma genealogia das categorias relativas à mobilidade, quando o termo êxodo aparece nos estudos em ciências sociais, vem destituído de agente. 
Os "flagelados", "retirantes" ou afins seriam limitados à condição de vítimas de catástrofes naturais ou sociais (tais como a seca), figuras passivas em seus deslocamentos. Já a migração não é comumente explicada em termos de cataclismas, mas aparece vinculada a amplos processos históricos relativos ao desenvolvimento econômico ou à industrialização. Em ambos os casos, são tratadas como categorias autoevidentes: "tanto quanto êxodo, a migração é um processo dado, empiricamente reconhecível, a que só podemos indagar sobre suas causas e consequências sociais, nunca sobre ele próprio" (:69).

Os autores apontam para a inexistência de um conceito sociológico de migração, sempre explicado de forma tautológica. Eles não pretendem propor um sentido alternativo, mas sim questionar a unidade estabelecida em torno da categoria. Não é necessário que a migração seja pensada como uma unidade distinta, podendo ser diluída em outros conjuntos de fenômenos. À medida que é tratada como um fenômeno uniforme, necessário ao controle de populações e atribuído a causas exteriores, a migração oblitera formas particulares de deslocamento e outros fenômenos aos quais pode estar articulada.

Partindo desta perspectiva e de seus desdobramentos, olho para os movimentos dos meus interlocutores, fugindo dos usos de migração e seus correlatos que a atribuem a situações de excepcionalidade ou como resultados de processos sociais supostamente inevitáveis (a urbanização, por exemplo) que apontariam, no limite, para o fim do campesinato ou do meio rural. Também procuro fugir do pressuposto de que se parte de um ponto A rumo a um ponto B previamente definidos, como se territórios fossem anteriores aos movimentos que os produzem. Ao contrário, eles são produzidos em ato, sendo a direção do movimento e o lugar da parada indissociáveis do próprio caminhar (Deleuze \& Guattari 2002 citados em Perutti 2015).

A distinção feita por Ingold entre o movimento do peregrino e o transporte nas sociedades metropolitanas modernas pode ser inspirador para a análise a ser feita. Segundo o autor, no transporte metropolitano moderno, o viajante não se move, mas é movido de um ponto ao outro, e o plano de rota preexiste à sua realização efetiva (2015:221, 225). Deste modo, a viagem seria transformada "de uma experiência de movimento na qual a ação e a percepção estão intimamente ligadas, em uma imobilidade forçada e privação sensorial" (:224). Diferentemente daquele que é transportado, o peregrino não tem destino final. Para ele, "o mundo não é apresentado como uma superfície a ser atravessada. Em seus movimentos, ele costura o seu caminho por este mundo, ao invés de atravessá-lo de um ponto a outro" (:223). 
Nesse sentido, podemos olhar o deslocamento de pessoas ou grupos de uma forma mais ampla, não como limitado a situações de exceção ou causas externas, com destinos preestabelecidos, mas considerando que a "caminhada é o modo fundamental como os seres vivos habitam a terra" (Ingold 2015:38). E, deste modo, mobilidade é também categoria analítica, ao não se restringir a um atributo do objeto, mas também a uma forma de olhar para pessoas e seres em suas relações.

Diversas etnografias tratam de práticas de deslocamento como um modo de ser e de habitar o mundo que é parte da vida que é vivida e, portanto, articula-se a outros temas, como os da casa, relações de parentesco, gênero e à própria existência, que podem ser intensificadas por situações excepcionais ou processos de urbanização, mas não são a eles redutíveis, de modo a não tratar o mundo como anterior ao movimento que o produz.

Desta forma, Machado explorou a articulação entre parentesco e movimento, argumentando que o movimento produz novos emaranhados de relações de parentesco ao mesmo tempo em que reconfigura diferenciações entre parentes (2014:138). No caso de Governador Valadares (MG), os deslocamentos dos filhos mais novos para fora das terras dos pais eram necessários para evitar um esgotamento espacial, resultando em hierarquias entre os irmãos (os que ficavam na terra estavam em posição superior). Com o passar do tempo, houve uma inversão de tais hierarquias e a imobilidade ganhou um valor negativo, sinônimo de falta de vivência. O autor também chama a atenção para o fato de família e parentesco serem feitos nos objetos colocados em circulação quando pessoas se movimentam (remessas de dinheiro e de bens), e supõe um agenciamento das relações (de maternidade, conjugalidade, entre outras) feito a distância. Por fim, estar em um novo lugar implica também o estabelecimento de novas alianças, casamentos e práticas de convivialidade no novo ambiente.

De modo similar, em Handerson Joseph (2015), Bongianino (2015) e Freire (2018), o movimento apresenta-se como uma forma de existência que é condição para a feitura das famílias africanas e afrodescententes. No caso haitiano, práticas de mobilidade sempre foram uma constante no cotidiano dessa população, e é por ela entendida como uma predestinação, uma obrigação ou um sonho a ser realizado (Joseph 2015:67), sendo parte constitutiva da dinâmica das relações de parentesco. Se conflitos políticos, situações de pobreza e cataclismas, tais como o terremoto de 2010, podem ajudar a explicar tais práticas, não são a elas redutíveis. O autor demonstra como o movimento é definidor daquilo que entendem como bem viver, e sair do país é algo tão constitutivo da vida dessa população que diversas práticas, coisas e pessoas a ela relacionadas foram incorporadas ao vocabulário 
créole, tais como dyaspora (em referência à mobilidade para fora do país, ou às pessoas que a praticam); dèpote (pessoa deportada); peyi blanc (país rico, bom para migrar e melhorar as condições de vida), ou kay dyaspora (casa formada por objetos adquiridos durante a diáspora, em oposição às casas locais). No caso dos cabo-verdianos que vivem em Nápoles, na Ítalia, Bongianino discute a mútua constituição entre mobilidade e parentesco, sendo que a primeira aparece como um valor necessário para a formação da pessoa (fazer crescer). Já em Freire, a mobilidade de mulheres negras de San Basílio de Palenque (Colômbia) está estritamente vinculada ao trabalho, sendo a forma por elas encontrada de agenciar uma possível ascensão social familiar.

Nessas etnografias, a mobilidade torna visível relações de gênero, existindo diferentes formas de fazer movimento entre homens e mulheres. É o caso de Alves (2015), Bonginiano (2015) e Freire (2018), que abordam o movimento do ponto de vista das mulheres e dos reforços nas redes de mulheres necessários para que possam se deslocar e deixar seus filhos, sendo as práticas de cuidado distribuídas entre elas. Criam-se, portanto, formas de cuidar e de manter vínculos ainda que a distância. Alves, por exemplo, analisou a mobilidade de mulheres de uma região do Vale do Jequitinhonha, procurando entender como as casas (raízes) acompanham as saídas e os retornos de suas moradoras. Inicialmente, as saídas da região eram majoritariamente masculinas, e as mulheres que permaneciam na localidade eram, com frequência, chamadas de viúvas de maridos vivos à medida que não conviviam com eles. Com o tempo, elas passaram a partir para trabalhar em casas de classe média alta no interior de São Paulo, o que impôs novas formas de criar os filhos e cuidar das casas, mantidas na localidade de origem (2015:17).

Já Guedes (2013) e Rumstain (2008) abordaram o movimento do ponto de vista masculino, analisando a socialidade de garimpeiros e peões, respectivamente, no norte de Goiás e no Maranhão, do ponto de vista de homens em seus constantes deslocamentos, "correndo o trecho", um movimento que Guedes caracteriza como apaixonado, carregado de uma intensidade própria, no caso, a atividade do garimpo. No trabalho de Guedes, movimento é pensado não apenas em sua concretude, mas também como forma de dar sentido ao mundo e que organiza pares de oposição entre códigos de instabilidade ("febre", "agitação") e de permanência ("sossego", ficar "parado"). Merece destaque o papel das mães na garantia da permanência, do enraizamento e da estabilidade, controlando a intensidade das "febres". O autor também discute as negociações intrincadas entre "andar", "correr o trecho" e cumprir com as obrigações familiares. 
Em comum, menos do que buscar causas primeiras para os deslocamentos, tais estudos procuram compreender suas dinâmicas e intensidades, as relações que produzem e reordenam, os seres, as gentes e os objetos que fazem circular.

\section{Deserto como falta, movimento como modo de vida}

No caso de meus interlocutores quilombolas, deslocamentos e permanências compõem um modo de vida particular. Dona Sebastiana, filha de "pai baiano e mãe kalungueira", nasceu nos vales do rio Paranã e foi criada em uma fazenda da região, onde o pai trabalhava como vaqueiro. Nessa mesma fazenda conheceu João Magalhães (falecido em 1977), também vaqueiro naquelas terras, e com ele se casou em 1944. João era kalungueiro e, na década de 1940, separou-se de sua primeira esposa e deixou o povoado Kalunga em que vivia, movimentando-se rio Paranã acima. De acordo com Sebastiana:

O negócio é igual o povo daqui que muda pra todo lado. De Brasília vai pra São Paulo... É caçando melhora. Porque o povo daqui está todo espalhado por esse mundo. [...] Veio ele [João] e três irmãos. E depois vieram os cunhados [irmãos de João], veio um bocado. [...]

Eles eram tudo de lá [do Kalunga], mas vai abrindo o mundo. É igual o povo de Bahia. Ô que já saiu baiano pra cá! [risos].

Conforme abordei em outro lugar (Perutti 2015), para Sebastiana, "abrir o mundo" para "caçar melhora" é o modo kalungueiro de viver, tendo em vista uma vida repleta de "precisão" (carência material). Tanto a "raça" do kalungueiro quanto a do baiano eram por ela consideradas "desinquietas". Um dos filhos de João e Sebastiana respondeu-me quando questionei sobre as andanças do pai que "não entende muito esse povo de antigamente", que nunca "aquietava", "andava demais da conta", "parece que era meio doido".

"Fugir da precisão" ou "caçar melhora" não é a única justificativa dada ao movimento de pessoas: ele também pode ser consequência de rupturas matrimoniais, indicando o caráter predominantemente masculino do deslocar-se de maneira constante, conforme indica o caso de João. Nesse sentido, caso uma mãe deseje que o filho fique menos "solto no mundo", deve incentivá-lo a se casar, embora nem sempre o casamento seja bem sucedido para essa finalidade. Não faltam casos nos quais o homem "abriu o mundo" para trabalhar e "arrumou outra mulher", ou colocou o casamento em risco pela falta de contato com a esposa, que ficou. 
Dificilmente uma mulher sozinha faz uma "andança": o deslocamento das mulheres ocorre junto com o marido e os filhos, quando há, como ocorreu com João e Sebastiana ao longo dos mais de dez anos após o casamento antes de se fixarem definitivamente no Lavado. Mas andar com filhos não é desejável, criar filhos impõe "aquietar" em alguma medida, e ter filhos é uma estratégia de muitas dessas mulheres de se enraizarem, ainda que temporariamente, em um mundo povoado de "desinquietação". É um modo de criar permanências espaço-temporais, de refrear a sina do pobre de "andar demais". Dar existência a filhos resultou no modo mais imediato encontrado por Sebastiana de permanecer no Lavado e, mais do que isso, de tecê-lo enquanto lugar.

Assim, de um modo geral, as mães podem ser vistas como produtoras de estabilizações impostas pela tarefa de criar filhos. De acordo com Sebastiana: "Mãe sofre pra criar menino. Pai fica ora aqui, ora acolá, mas mãe fica todo o tempo". Mãe é aquela que fica, e ficar pode ser sofrido caso o pai esteja numa "andança".

Andar servia para obter trabalhos temporários, procurar um lugar melhor para fazer uma roça ou um criatório, quando o anterior não estava a contento, conhecer novas pessoas. Já para alguns dos filhos de João e Sebastiana, que passaram a maior parte da vida numa terra só, não há "precisão" que justifique tanto andar, para eles isso era mesmo "ideia doida desse povo de antigamente".

Dessa primeira descrição sobre um modo de ser kalungueiro - em movimentos contínuos pelas beiras do rio Paranã, e por vezes além rio concluímos que estar no deserto, ou perto dele, demanda andar: anda-se para fugir do sofrimento, da carência material, em busca de "melhora"; anda-se com o intuito de estabelecer novas relações, quando as anteriores parecem não bastar para minimizar a percepção de ausência de gente. $\mathrm{O}$ deserto que impulsiona as andanças aparece como lugar da falta, do vazio, do limite, e pode ser causa de "desinquietações".

Assim sendo, é também a partir da iminência do "deserto" que kalungueiros e Magalhães produzem suas formas de existência, o que o dota de um sentido positivo, como potência criativa, de onde brotam territórios. Deleuze e Guattari (2002) fazem uso da imagem do deserto em referência ao território nômade, espaço liso, aberto, não codificado, em oposição ao espaço estriado do sedentário (linear, mensurável, com forma predefinida, relativo aos paradigmas da ciência e do Estado). A referência diz respeito, antes de tudo, a um modo de estar no mundo em que relações são centradas em experimentações e afetos. 


\section{Deserto que mobiliza saberes}

Estar na iminência do deserto implica fazer do movimento, próprio ou alheio, uma forma de saber. A Fazenda Lavado, território de meus interlocutores, é cortada pela estrada de terra construída pela Vale no período do garimpo, e é também por meio dela que controlam, em um treino apurado da percepção, a circulação de pessoas e seres pela localidade, avaliando se o lugar está movimentado ou deserto.

Enquanto estive na localidade, minhas "andanças" eram controladas pelo rastro de tênis que deixava na estrada, e esses rastros eram comentados comigo, como forma de as pessoas demonstrarem estarem a par de meus movimentos. Perguntavam-me, de modo a confirmar suas especulações, se no dia anterior eu havia ido à determinada casa visitar alguém. Assim como o andar da pesquisadora, as passagens de um tatu, vaca, pessoa a cavalo, de bicicleta, de caminhonete, o rastejar de uma cobra são cotidianamente identificados pelo observador atento, e também o tempo em que ocorreu aquele deslocamento: se recente ou já antigo. O período de chuvas, entre outubro e março, facilita essa identificação temporal da movimentação pelo tipo de rastro deixado no barro, se ainda úmido ou já seco. Antes da construção da estrada de terra, este tipo de controle da passagem de gentes e bichos ocorria, porém era mais difuso, já que as áreas de circulação eram limitadas a pequenas trilhas no meio da mata, e pessoas muitas vezes optavam por fazer caminhos alternativos, abrir novas picadas. A "estrada de chão" aprimorou o controle dos movimentos, formando uma espécie de moldura, que enquadra as múltiplas marcas das passagens de seres pelo Lavado. E, mais do que simples indícios de movimento, os rastros são movimento, na medida em que o observador os experimenta, compõe com ele um saber, além de recortar aqueles que o interessam para construir sua narrativa sobre circulações ocorridas no Lavado.

Quando há poucos rastros impressos na estrada, seja de bicho ou de gente, lamenta-se que o lugar esteja deserto demais. Do mesmo modo, uma estrada cheia de rastros de tipos diversos alivia a percepção de deserto ou de se estar no buraco, dá margem a especulações. Portanto, ao serem experimentados pelo observador de percepção treinada, os rastros não se limitam a representar movimentos passados em uma forma acabada, fixados no barro e à disposição de um espectador passivo. Ao contrário, o papel de meus interlocutores em relação a esses vestígios é ativo, à medida que criam narrativas sobre relações entre seres a partir do entrecruzamento de rastros, dão risada de caprichos do acaso como o pé de uma criança bem no meio de uma pata de gado, ou quando o passo curto de algum parente é 
comparado ao de algum animal. Com o cálculo dos tempos de passagem das pessoas, tendo em vista o tipo de marca deixado no chão, também é possível imaginar supostos encontros entre seres que por ali passaram na mesma hora. Em suma, a estrada está muito além de um espaço bidirecional que vincula um lugar específico a outro. Existem inúmeros movimentos possíveis a partir dela, linhas de fuga, que possibilitam aos meus interlocutores movimentarem-se sobre outros movimentos, relacionando gentes e seres.

Além disso, a estrada evidencia o deserto como lugar de espera, uma espera que aguça os sentidos. Aqueles que têm a sua casa construída em sua beira estão sempre no aguardo da passagem de algo ou de alguém. Os ouvidos ficam atentos à "zoada" do motor de algum veículo, identificado a distância. É comum especularem, apenas pelo som ouvido ao longe, que se trata de um carro ou de uma moto, quem deve ser o dono, qual a sua distância e em que direção está indo. Há, assim, um constante estado de alerta em busca desses sinais, e a sua ausência desertifica lugares.

\section{Deserto como travessia}

Para além de lugar da falta, fim ou destino de onde se deve fugir, "deserto" pode ser também travessia. Já mencionei que, para meus interlocutores, andar no deserto é com frequência associado ao sofrimento, onde é possível passar por provações capazes de transformar seres e pessoas, algo presente na tradição judaico-cristã. É no deserto que o povo hebreu, guiado por Moisés, inicia sua "andança" para fugir de uma situação de escravidão, no Egito, em busca da terra prometida. No Novo Testamento, foi no deserto que Jesus jejuou por 40 dias e foi tentado, por três vezes, pelo diabo, tendo recusado suas ofertas. O diabo teria tentado Jesus a transformar pedras em pães, de modo a aplacar a fome. Em seguida, que saltasse do pináculo do templo, de modo que os anjos o salvassem. Na última tentação, o diabo levou Jesus a um monte muito alto de onde era possível ver todos os reinos do mundo, e os ofereceu caso Jesus o adorasse. Jesus recusou, no deserto, a oferta do mundo pelo diabo e, após esse episódio, os anjos de Deus se aproximaram e o serviram em recompensa (Matheus 4:1-11).

$\mathrm{O}$ andar no deserto, para um Magalhães, transforma moralmente uma pessoa, que é respeitada por ter, no passado, andado demais, em uma vida de sofrimento. A associação recorrente entre o andar demais e o sofrer demais é ainda maior se esse andar é feito com as mães carregando filhos pequenos. E sua materialidade também não deve ser ignorada: o andar da vida sofrida é feito a pé ou em lombo de burro, debaixo do sol quente, com o peso dos filhos na cacunda. ${ }^{13}$ Conforme a fala de um Magalhães: 
Ele [João] mudou pra cá porque as coisas lá eram difíceis demais. Agora que está melhor. Aí ele não aguentou o sofrimento lá [no Kalunga]. Porque lá era andar a pé ou no lombo de animal, os que tinham. E eram quase umas vinte léguas pra vir pro conforto cá.

Os jovens, por terem nascido com mais conforto material, sem a necessidade de passar pelo desgaste físico de uma "andança" nos moldes antigos, são acusados de não saberem valorizar o que têm. Fui vista com estranheza e alvo de piada por parte dos Magalhães, sendo chamada de "paulista, mas sofredora", por gostar de andar, e andar três, quatro quilômetros a pé entre uma casa e outra do Lavado. ${ }^{14}$

Contudo, é necessário ponderar a existência de diversas modalidades de "andança", e o fato de que andar nem sempre é sinônimo de sofrimento ou prática moralmente valorizada. Como foi dito, o andar em família para fugir do deserto e "caçar melhora" é, no mais das vezes, um andar sofrido. Há "andanças", feitas ou não em família, que são propriamente kalungueiras, tendo as beiradas do rio Paranã como referencial. Mais recentemente, são frequentes as idas para a cidade grande, Brasília ou Goiânia, dos mais jovens para estudar ou trabalhar. Com destino inicialmente predefinido, ainda que com frequência alterado, tais "andanças" são narradas como tranquilas, feitas "no conforto" de um carro ou de um ônibus. Há também casos de homens deslocando-se sozinhos "para abrir o mundo", em trabalhos temporários em fazendas no oeste da Bahia, Minas Gerais ou municípios vizinhos. Nos dois últimos casos, volta-se ciclicamente para as casas das mães ou das esposas sem que isto seja necessariamente entendido como um sofrimento.

É comum ouvir a expressão "abrir o mundo" para se referir aos deslocamentos para lugares pouco conhecidos ou sem um trajeto e destino previamente definidos. Neste caso, deserto não deve ser entendido como sinônimo de mundo, ainda que ambos possam ser espaços lisos, não codificados. No "mundo", a ênfase está no desconhecido a ser percorrido, um espaço que se abre ("abrir o mundo"), um território que ganha existência com o próprio ato de caminhar. Já o deserto está, no mais das vezes, associado à falta (de gentes, de relações) e ao vazio que impulsiona movimentos dos quais se pode sair moralmente superior. O mundo não necessariamente é deserto, ainda que possa sê-lo. Do mesmo modo, lugares bem conhecidos podem se desertificar, demandando uma "andança". ${ }^{15}$

Para que esse andar seja moralmente valorizado, é preciso saber parar. Um homem que só anda e nunca para é julgado negativamente por não conseguir se "firmar" com mulher nenhuma, por não ter casa ou por ter se esquecido da sua. Pessoas ou famílias que só andam são, com frequência, 
definidas como "doidas". E é preciso lembrar que nunca se sai totalmente do deserto só no caminhar: nas paradas e nas permanências são feitos os amigos, os compadres, que o monturo se acumula atrás do terreiro. E, aqui, parto para um último sentido de deserto, apresentado pelos meus interlocutores e associado às já mencionadas permanências e à atuação das mulheres.

Deserto como ponto de origem: dona Sebastiana encontra seu Antônio

Quando João faleceu, Sebastiana ainda não havia terminado de criar todos os seus 11 filhos, e esse período é narrado como de grande sofrimento. Ela conta que estava só e não recebeu "ajuda de fora" para criá-los. Aquelas que a teriam ajudado foram as filhas mais velhas, que participavam do cuidado com os mais novos.

Ela considera que os filhos cresceram no deserto, pois o Lavado, no início, estava distante de quaisquer vizinhos. Por esta razão, pôde criá-los com temperamento calmo e sem vícios em cigarro, bebida ou "malandragem" (Sebastiana fuma e bebe, mas não deixou que seus filhos tivessem os mesmos vícios). Há, desse modo, um agenciamento da mãe na produção do caráter de seus filhos, resultado de um ato de criação que só foi possível ao se fixarem definitivamente num lugar. Nesse sentido, para os Magalhães, deserto é tanto ausência de gentes e de relações, de que se afastam à medida que são propensos a produzir amizades, quanto condição original e necessária para se fazerem "amigueiros", pois só teriam tal temperamento porque a mãe os criou "no deserto".

Dito de outro modo, se considerarmos o deserto como um lugar de provação, uma travessia dea qual se sai moralmente superior em relação ao momento de entrada, um ato de criação ocorrido no deserto pode ser responsável pela consolidação dos atributos morais necessários para que os Magalhães se façam enquanto "raça amigueira". Sebastiana dá, assim, um nó nas definições de deserto trabalhadas até então e oferece a possibilidade de pensá-lo não como espaço vazio, da falta, mas espaço cheio, lugar originário e de indistinção, onde a relação entre mãe e filhos ocorre plenamente, sem interferência do "mundo". Este último sentido de deserto o afasta definitivamente daquele de mundo. Por um lado, João Magalhães teria transmitido suas qualidades de "amigueiro" aos seus descendentes pelo sangue e, por outro, foi a permanência da mãe com os filhos no deserto que os fez amigueiros, e tal permanência ofereceu as condições necessárias para que dele saíssem, em razão de seu modo de ser e de se relacionar. Aqui, deserto desloca-se do fim para a origem. 
Contudo, ainda que valorizado como lugar originário, a permanência no deserto deve ser temporalmente circunscrita. Viver em definitivo no deserto, tomar o deserto para si, é algo perigoso, coisa de "gente doida". Este é o caso do Seu Antônio, narrado no início deste artigo, que partiu para o meio do mato e ali fez sua morada embaixo do chão.

Antônio fez do deserto seu lugar, intensificou uma potencialidade de Nova Roma da qual seus habitantes procuram se afastar. O incômodo produzido pelo seu ato é capaz de explicitar as qualidades semânticas de deserto aqui narradas. Mas, diferentemente de Sebastiana, viver no deserto assumiu, para ele, um caráter permanente, o que o torna "doido", assim como aquele que anda demais, sem ponto de parada. Seja como lugar originário, seja como lugar por onde se anda, é preciso saber sair do deserto, pois só assim ele se mantém como potência criativa, de onde se produzem territórios.

\section{Considerações finais}

Neste artigo, procurei discutir as variações semânticas em torno de deserto e sua relação com movimento com meus interlocutores quilombolas de Nova Roma. Uma acepção mais imediata do termo, com a qual tive contato assim que iniciei a pesquisa, o associa a um (não) lugar indesejável, de onde se procura fugir e que impulsionaria êxodos ou migrações em massa. As causas para tal evasão de pessoas são múltiplas, e com frequência atribuídas ao desemprego, a danos ambientais (como os proporcionados pelo garimpo), às condições climáticas desfavoráveis, como a seca, algo discutido por Palmeira e Almeida (1977). Nesse primeiro sentido, deserto pode referir-se a lugares não alcançados por instâncias estatais ou por elas alcançados de forma predatória, negando a existência de gentes e seres que o habitam.

No entanto, nem sempre a invisibilidade diante do Estado foi vista negativamente. Quando negros escravizados em fuga encontraram as serras e os vales do rio Paranã, a dose de invisibilidade que o lugar lhes proporcionava era essencial para garantirem sua existência em liberdade, o que não significava isolamento. Com o tempo, kalungueiros fizeram do deserto potência criativa, a partir dele estabelecendo seu modo de ser. É nele que os Magalhães percorrem suas trilhas, entrelaçam movimentos, produzem-se continuamente enquanto povo "amigueiro", cultivam relações de vizinhança, intervêm nas ações do Incra, de modo a manterem seus vizinhos a despeito do tamanho da terra a ser titulada. Ser "amigueiro" é, por um lado, condição necessária para que saiam do deserto e, por outro, o deserto é necessário para que produzam esse modo de ser e de se relacionar. 
Neste ponto, Sebastiana torce os sentidos mais correntes de deserto, fazendo dele lugar originário de um ato de criação, um topos onde mães podem criar seus filhos em condições ideais, sem interferência do "mundo" (ainda que com boa dose de sofrimento). Contudo, não se fica permanentemente no deserto, mas apenas em suas proximidades, sob sua iminência, ou, ainda, adentra-se o deserto para dele melhor sair. A produção contínua de relações, que faz de um Magalhães "amigueiro", depende de um saber avaliar a melhor hora de andar e de parar, em um jogo contínuo entre movimentos e estabilizações, compondo o aprendizado de se viver no limite da existência.

Recebido em 13 de fevereiro de 2020

Aprovado em 05 de maio de 2021

Daniela Perutti é mestre e doutora em Antropologia Social pelo PPGAS-USP. Foi pós-doutoranda do PPGS-UFF, professora substituta do Instituto de Saúde e Sociedade da Unifesp e assessora de programas da Comissão Pró-Índio de São Paulo. Atualmente, é pesquisadora da Plataforma de Antropologia e Respostas Indígenas à Covid-19 (PARI-C), do Hybris (Grupo de Estudo e Pesquisa sobre Relações de Poder, Conflitos, Socialidades) e do NuAP (Núcleo de Antropologia da Política). Desenvolve pesquisas junto a comunidades rurais e quilombolas, com ênfase em política, família, meio ambiente, relações de gênero e território. https://orcid.org/0000-0002-9449-1087

E-mail: danielaperutti@gmail.com 


\section{Notas}

1 Este artigo é o resultado de muitos diálogos e interlocuções, e uma versão preliminar foi apresentada na 31 ${ }^{\mathrm{a}}$ RBA (2018) e nos Seminários de Antropologia e Filosofia da Unifesp (2019). Agradeço ao André Guedes e à Candice Vidal, organizadores do primeiro evento; e a Jorge Villela, Alexandre Pereira e Alexandre Carrasco, organizadores do segundo, bem como aos participantes de ambos os eventos pelos importantes debates que fomentaram. Também agradeço ao parecerista anônimo desta revista pelas sugestões.

2 Reportagem disponível em: http://g1.globo.com/goias/videos/v/juiz-visitaburaco-onde-homem-vive-ha-25-anos-para-decidir-sobre-acao/4576528/. Acesso em 05/12/2019.

3 Este artigo apresenta parte dos resultados de minha pesquisa de doutorado realizada junto ao quilombo Família Magalhães, no nordeste goiano (Nova Roma), entre fevereiro de 2011 e dezembro de 2015. A pesquisa contou com períodos de trabalho de campo na comunidade, realizados entre 2012 e 2014, além de idas pontuais a Goiânia, onde vive parte do grupo, em 2015. Pretendo sistematizar um aspecto que aparece de forma dispersa na tese, a saber: as variações semânticas em torno de deserto, e sua relação com movimento, entre os quilombolas da região, de modo a alargar os sentidos de território a partir de outras formas de habitar o mundo.

4 Farei uso de aspas duplas para palavras ou expressões usadas por meus interlocutores.

5 Uso de empréstimo a expressão negação da coetaneidade que Fabian (2013) lança mão para se referir ao uso do tempo pelos antropólogos modernistas, que colocariam os interlocutores de suas etnografias em um tempo outro, indeterminado, exterior ao tempo do antropólogo.

6 A percepção de que municípios estão próximos do fim não é uma exclusividade de Nova Roma, e está amplamente presente nos discursos dos moradores das regiões Norte e Nordeste de Goiás, a exemplo da etnografia de André Dumans Guedes (2013) a respeito de Minaçu (GO).

7 O "tempo da política", categoria presente em diversos contextos etnográficos, corresponde ao período eleitoral mas, segundo Palmeira e Heredia (2010:8), esta não é a sua tradução exata. Trata-se de um tempo que envolve toda a população, cujo cotidiano é subvertido por rituais e interdições próprias. No "tempo da política", está em jogo um rearranjo das posições sociais por meio da adesão a um determinado lado na disputa eleitoral.

8 A afirmação de Cleary a respeito da variação populacional nos garimpos da Amazônia certamente se aplica a essa situação: "Mesmo que fosse realizado um censo completo de todos os garimpos da Amazônia, ainda assim os dados não seriam confiáveis. A população dos garimpos flutua consideravelmente, os garimpeiros se 
mudam para outras regiões de garimpagem ou retornam para a cidade e campo com a mudança da chuva, com a mudança do calendário da agricultura e com as flutuações da economia urbana" (1992:2).

9 Segundo me explicou, monturo designa o local atrás da cozinha onde são acumulados e queimados os restos de comida.

10 Assim enuncia o Artigo 68 da ADCT: "Aos remanescentes das comunidades dos quilombos que estejam ocupando suas terras é reconhecida a propriedade definitiva, devendo o Estado emitir-lhes os títulos respectivos".

11 Sobre esse episódio, ver Almeida (2008) e Perutti $(2015,2018)$.

12 Importante chamar a atenção para o conceito de habitar, inspirado em Heidegger, que se distingue do de morar. Para Ingold, a vida é vivida através ou em torno de lugares, e não dentro de lugares, que por sua vez seriam definidos pelo próprio movimento, e não por seus limites externos. Assim, pessoas que frequentam lugares são habitantes, e não moradoras (:220).

13 No episódio da Fuga da Sacra Família para o Egito, José e Maria também fogem carregando Jesus no lombo de um burro.

14 Encontrei acepção semelhante na etnografia de Maíra Samara Freire, na qual mulheres negras de San Basílio de Palenque, na Colômbia, percorrem longas distâncias para vender seus doces, em jornadas exaustivas, deixando o cuidado com os filhos a cargo de outras mulheres. Esse caminhar carregado de sofrimento é também moralmente valorizado, e feito para se garantir um melhor futuro aos filhos. Nesse sentido, elas definem seus corpos como aqueles que tudo aguentam. "O corpo que tudo aguenta é o que elas têm, e o que lhes resta como mecanismo de agência num universo social que não permite para elas perspectivas melhores" (2018:204).

15 Uma noção cujo sentido pode se aproximar de deserto, embora não coincida com ele, é a de roça. Em certa ocasião, um de meus interlocutores lamentou que "se a prefeitura não existisse mais aqui, Nova Roma acabava. Virava Roça". Discuti em Perutti (2015) a multiplicidade de sentidos de roça, que inclui áreas de cultivo e lugares de boas festas. No entanto, "roça" também pode ser pensada menos como um lugar previamente definido e mais como um termo de falta numa comparação, um lugar é "roça" em relação a outro com o qual se compara: assim, diante do garimpo de cassiterita (que mobilizou milhares de pessoas para serras da região nos anos 80), Nova Roma era "roça". Ou seja, a cidade, seu centro urbano, foi menos capaz de mobilizar gentes do que foi o garimpo. Também ouvi comparações entre municípios, em que se dizia que um era "roça" perto de outro. Mas não basta ser capaz de mobilizar pessoas para que um lugar seja mais ou menos roça. "Virar roça" também pode se relacionar a estar mais apartado do mundo da lei, do Estado, que codifica espaços, constrói rodovias ("BRs"), atrai "firmas". Neste caso, "roça" se aproxima da ideia de espaço vazio contida em "deserto", ainda que os demais sentidos a ela associados (cultivo, roçado, festa) dele se afastem. Além disso, dificilmente deserto é usado como termo de comparação (ser mais ou menos deserto), como ocorre com roça. 


\section{Referências bibliográficas}

ALMEIDA, Roberto. 2008. "Não podemos jogar pedra em amigo: uma comunidade quilombola definindo suas fronteiras". Anais da $26^{a}$ Reunião Brasileira de Antropologia. Goiânia: UCG.

ALVES, Yara. 2015. A casa raiz e o voo de suas folhas: família, movimento e casa entre os moradores de PinheiroMG. Dissertação de Mestrado em Antropologia Social, PPGAS/USP.

BONGIANINO, Claudia. 2015. "Crescendo pessoas, relações e lugares: experiências cabo-verdianas sobre família e mobilidade". Cadernos Pagu, n. 45:111-133.

CLEARY, David. 1992. A garimpagem de ouro na Amazônia: uma abordagem antropológica. Rio de Janeiro: Ed. UFRJ.

DELEUZE, Gilles \& GUATTARI, Félix. 2002. Mil platôs: capitalismo e esquizofrenia. Vol. 5. São Paulo: Ed. 34.

FABIAN, Johannes. 2013 [1983]. O Tempo e o Outro: Como a Antropologia Estabelece Seu Objeto. Rio de Janeiro: Editora Vozes.

FREIRE, Maíra Samara. 2018. Doce, suor e lágrimas: trabalho, gênero e família em uma comunidade negra do Caribe colombiano (San Basílio de Palenque). Tese de Doutorado em Antropologia Social, PPGAS/MN/ UFRJ.

GUEDES, André Dumans. 2013. O trecho, as mães e os papéis. Etnografia de movimentos e durações no norte de Goiás. Rio de Janeiro: Garamond.

INGOLD, Tim. 2015 [2011]. Estar vivo: ensaios sobre movimento, conhecimento e descrição. Petrópolis: Vozes.
JOSEPH, Handerson. 2015. Diáspora: as dinâmicas da mobilidade haitiana no Brasil, no Suriname e na Guiana Francesa. Tese de Doutorado em Antropologia Social, PPGAS/MN/ UFRJ.

KUBITSCHEK, Juscelino. 2010 [1960]. "Discurso de JK na inauguração de Brasília (Brasília, 21 deabril de 1960)". In: Luíza Helena Nunes Pinto (org.), Discursos selecionados do Presidente Juscelino Kubitschek. Brasília: Fundação Alexandre de Gusmão.

MACHADO, Igor. 2014. "Migração, deslocamentos e as franjas do parentesco". Revistade @ntropologia da UFSCar, v. 6, n. 2:130-145.

PALMEIRA, Moacir \& ALMEIDA, Alfredo Wagner. 1977. "A invenção da migração". Relatório de pesquisa, Projeto Emprego e Mudança Socioeconômica no Nordeste.

PALMEIRA, Moacir \& Heredia, Beatriz. 2010. Política ambígua. Rio de Janeiro: Relume Dumará.

PERUTTI, Daniela C. 2015. Tecer amizade, habitar o deserto: uma etnografia do quilombo Família Magalhães. Tese de Doutorado em Antropologia Social, PPGAS/USP. . 2018. "Políticas do território e territórios da política em uma família quilombola de Goiás". In: Ana Claudia D.R. Marques \& Natacha S. LEAL, Alquimias do parentesco: casas, gentes, papéis, territórios. São Paulo e Rio de Janeiro: Terceiro Nome / Gramma.

RUMSTAIN, Ariana. 2008. Peões no trecho: estratégias de deslocamento e trabalho no Mato Grosso. Dissertação de Mestrado em Antropologia Social, PPGAS/MN/UFRJ. 
MOVIMENTOS E(M) DESERTOS:

AS TRILHAS DA EXISTÊNCIA

ENTRE QUILOMBOLAS DE

GOIÁS

Resumo

Neste artigo, exploro as variações semânticas da noção de deserto e sua relação com movimento entre os quilombolas de Família Magalhães (Nova Roma, GO). O grupo é originário dos kalungas, negros escravizados em fuga que viviam, desde o século 17, escondidos pelos vales do rio Paranã. A dose de invisibilidade que a região lhes proporcionava foi essencial para garantir sua existência em liberdade. Se hoje a região é tida pelos munícipes como lugar de falta, um deserto em vias de desaparecer, os Magalhães fazem dela potência criativa. É sob a iminência do deserto que tais quilombolas percorrem suas trilhas, entrelaçam movimentos, se produzem continuamente enquanto povo "amigueiro", cultivam relações de vizinhança, intervêm nas políticas públicas sobre suas terras. Cultivar relações de amizade é, por um lado, condição necessária para que saiam do deserto e, por outro, o deserto é necessário para manterem o seu modo ser.

Palavras-chave: Mobilidade, Goiás, Quilombo, Território, Amizade.
MOVIMIENTOS EN LOS DESIERTOS: LOS SENDEROS DE LA EXISTENCIA ENTRE LOS QUILOM BOLAS DE GOIÁS

\section{Resumen}

En este artículo exploro las variaciones semánticas de la noción de desierto existentes entre los quilombolas de la Familia Magalhães (Nova Roma, GO) y su relación con el movimiento. El grupo tiene su origen entre los kalungas, esclavos que, desde el siglo XVII, huyeron y vivieron escondidos en los valles del Río Paranã. La condición de invisibilidad que proporcionaba la región fue esencial para garantizar su existencia en libertad. Y si hoy para los habitantes del municipio esa región es un lugar de falta, un desierto en vías de desaparición, para los Magalhães es un lugar que han transformado en potencia creativa. Es en el desierto inminente que estos quilombolas recorren sus senderos, entretejen movimientos, se producen continuamente como un pueblo "amigueiro", cultivan relaciones de vecindad e intervienen en las políticas públicas sobre sus tierras. Para ellos, cultivar relaciones de amistad es condición necesaria para salir del desierto, así como el desierto es, por otro lado, necesario para mantener su manera de ser.

Palabras clave: Movilidad, Goiás, quilombo, territorio, amistad. 


\title{
MOVING THROUGH DESERTS: \\ TRAILS OF BEING AM ONG \\ MAROONS IN GOIÁS
}

\begin{abstract}
In this article, I explore the semantic variations of the notion of desert, and its relation to territory and movement among the maroon community 'Família Magalhães' (Nova Roma, Goias, Brazil). This community descends from the Kalunga, who were a large group of enslaved people hiding in the valleys of the Paranã river between the $17^{\text {th }}$ and $19^{\text {th }}$ centuries. Difficult access to this region ensured that the Kalunga could live and thrive as free men and women. Although people now living in the town of Nova Roma say that it lacks everything, and that the whole region is fading into a desert, the Magalhães are able to extract its creative potency. It is under the shadow of this seemly inescapable desert that the Magalhães wander through their trails along the Paranã river, cultivate relationships in the neighborhood, and intervene in public policies concerning their land. They constantly produce themselves as an "amigueiro" (friendly) people, but always in relation to the desert that is and ought to be. For the Magalhães, cultivating friendships is a necessary condition for leaving the desert, but, at the same time, the desret is necessary for their way of being.
\end{abstract}

Keywords: Maroon communities, friendship, territory, mobility, Goiás. 